\title{
Cultivo de tejidos vegetales para propagar y conservar especies mexicanas amenazadas
}

\author{
Culturing plant tissue to \\ propagate and conserve \\ threatened Mexican species \\ Susana Hernández Sánchez \\ he383196@uaeh.edu.mx \\ https://orcid.org/0000-0002-9352-4|58 \\ Universidad Autónoma del Estado de Hidalgo \\ Recibido: I de octubre de 202 I \\ Aceptado: 19 de octubre de 2021 \\ Publicado: 5 de enero de 2022
}

\section{Resumen}

México está catalogado como un país megadiverso, cuenta con amplia diversidad biológica y cultural. Además, destaca como uno de los países que son centro de origen y domesticación de plantas importantes, teniendo en el territorio nacional entre el 10 al $12 \%$ de todas las especies del mundo, y de estas el 50 al $60 \%$ son endémicas. Lamentablemente mucha de esta riqueza se encuentra sujeta a protección especial, amenazada, o en peligro de extinción. El cultivo de tejidos vegetales es una herramienta biotecnológica que permite la obtención de plantas de manera rápida, eficiente y en grandes cantidades, convirtiéndose en una estrategia para mitigar los problemas que enfrentan algunas especies. Por lo tanto, es importante el uso de la ciencia y tecnología en la recuperación de especies mexicanas, así como fomentar su estudio, propagación y conservación con el fin de realizar propuestas de aprovechamiento sustentable de la flora mexicana.

Palabras clave: Propagación, conservación, biodiversidad, flora.

\section{Biodiversidad mexicana en riesgo de desaparecer}

México es uno de los países más diversos del planeta, pues no solo tiene gran diversidad cultural a lo largo del país, sino que gracias a su posición geográfica tiene todos los climas para poder dar vida a diferentes especies, y a pesar de que ocupa solamente el $1.5 \%$ de la superficie terrestre del planeta, se estima que en nuestro país habita entre el 10 al 12\% de las especies del mundo, colocándolo así en quinto lugar de países megadiversos. Además, se calcula que entre el 50 y $60 \%$ de las especies de plantas vasculares que se conocen en el territorio mexicano son endémicas, entre ellas se encuentran algunas orquídeas y cactáceas (SEMARNAT, 2012).

\section{Abstract}

Mexico is classified as a megadiverse country for its broad biological and cultural diversity. In addition, Mexico is one of the most important countries with respect to the origin and domestication of plants worldwide. Some 10 to $12 \%$ of all plant species in the world grow in Mexico, of which 50 to $60 \%$ are endemic. Unfortunately much of this wealth is under special protection, threatened, or in danger of extinction. Plant tissue culture is a biotechnological tool that enables plants to be cultivated efficiently and in large quantities. As such, it is a useful strategy to mitigate the problems faced by some species. It is important that science and technology be used to help Mexican species recover, as well as to promote their study, propagation and conservation in order to make proposals for the sustainable use of Mexican flora.

Keywords: Propagation, conservation, biodiversity, flora. 
Cabe mencionar que México se destaca como uno de los países que han sido el centro de origen de plantas cultivadas de importancia para la humanidad, como el cacao, maíz, chile, vainilla, entre otras más. También tenemos familias vegetales de valor económico a nivel nacional e internacional, como lo son los agaves (Agavaceae), cactáceas (Cactaceae), leguminosas (Fabaceae), tomate, chile (Solanaceae), y flores como el girasol y la dalia (Asteraceae).

De este modo se esperaría que la biodiversidad mexicana se encuentre protegida, conservada y utilizada de forma sustentable. Sin embargo, con el paso de los años, esta biodiversidad se encuentra en peligro de desaparecer debido a los cambios constantes que sufren los ecosistemas derivados del cambio climático global, incendios forestales, sobreexplotación de recursos naturales, urbanización, surgimiento de nuevas enfermedades que afectan los cultivos, cambio de uso de suelo, tráfico ilegal y especies invasoras. Por lo tanto, resulta claro la falta de apoyo para el rescate de la flora mexicana.

En México, la NOM-059-SEMARNAT-2010 enlista las especies que se encuentran en riesgo de extinción, amenazadas o sujetas a protección especial. Dentro de los criterios que se utilizan para categorizar las plantas en riesgo es su distribución geográfica (área de distribución menor o igual a $1 \mathrm{~km}^{2}$ ), demografía (número total de individuos igual o menor que 500), nivel de impacto de las actividades humanas sobre el taxón y si la especie tiene poblaciones hiperdispersas (con una densidad de población de 1 individuo por cada 5 hectáreas o menor). De acuerdo con esta norma, el grupo de plantas con mayor riesgo son las cactáceas, orquídeas, palmas y agaves, los cuales han perdido drásticamente sus áreas de distribución y tamaño de sus poblaciones, pues se encuentran amenazadas por el impacto de las actividades humanas sobre su hábitat natural.

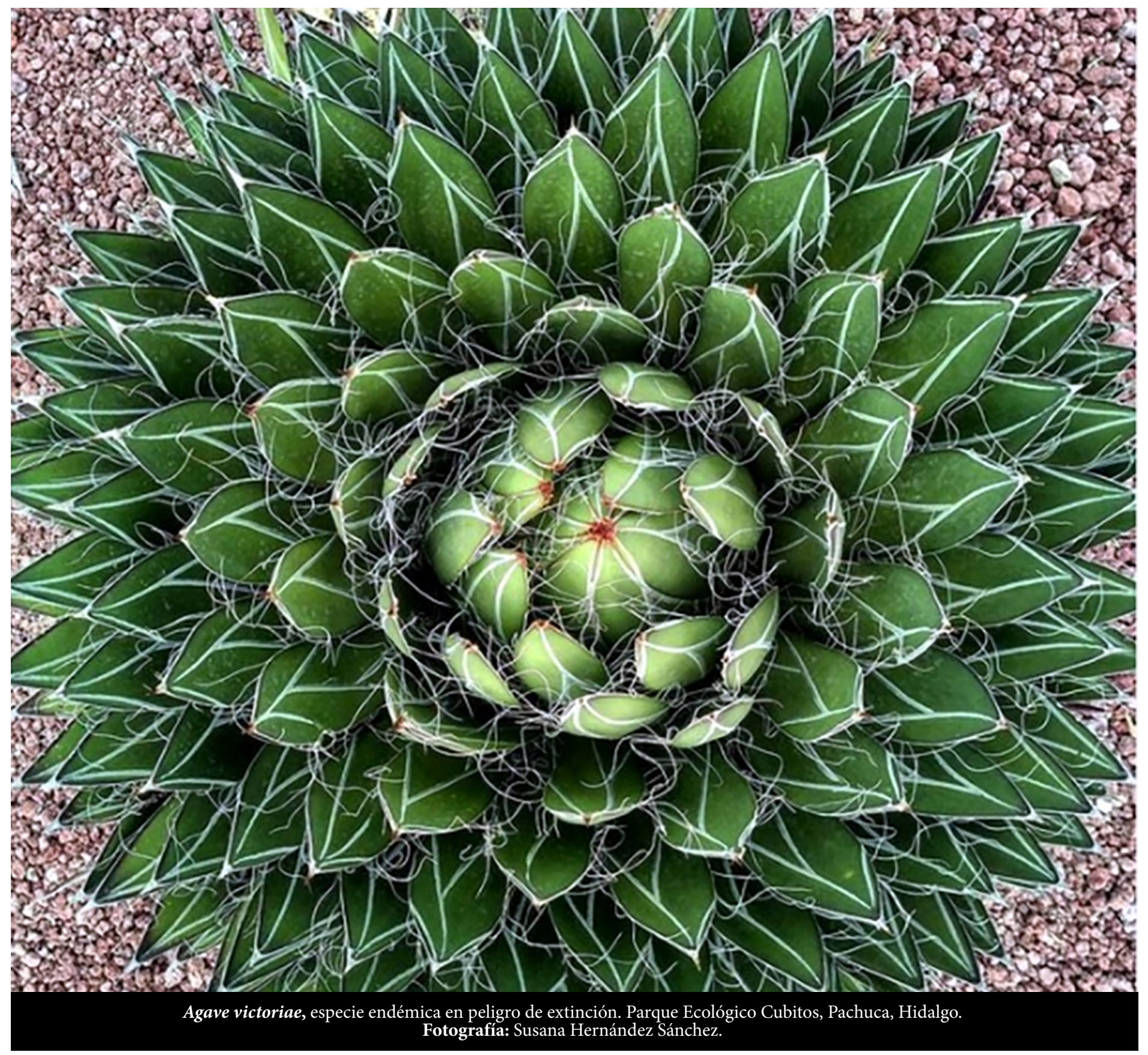


Técnicas biotecnológicas: Cultivo de tejidos vegetales

El cultivo de tejidos vegetales (CTV), es un método biotecnológico que permite producir plantas completas a partir de pequeños fragmentos de una planta de interés, también llamados explantes. Mediante el establecimiento, mantenimiento y manipulación de las células vegetales bajo condiciones artificiales (nutrientes, hormonas de crecimiento, luz, humedad, temperatura y $\mathrm{pH}$ ) se reproducen de manera aséptica órganos vegetales, hasta la obtención de plantas completas de manera rápida, eficiente y en grandes cantidades (Domínguez-Rosales et al., 2008). En efecto, es una herramienta que permite estudiar, propagar, conservar y hacer propuestas de aprovechamiento sustentable (Chávez-Ávila, 2014) en especies de interés comercial y plantas que se encuentran bajo una categoría de riesgo, de esta manera se contribuye a su persistencia contrarrestando la velocidad de consumo que sufren actualmente. Por consiguiente, reproducir y conservar nuestra riqueza biológica asegura la existencia de futuras generaciones.

Es claro el amplio potencial de esta tecnología, no solo en la conservación del material vegetal o germoplasma, también se utiliza en el mejoramiento genético, la micropropagación, la sanidad vegetal y la producción de compuestos químicos, entre otras aplicaciones.

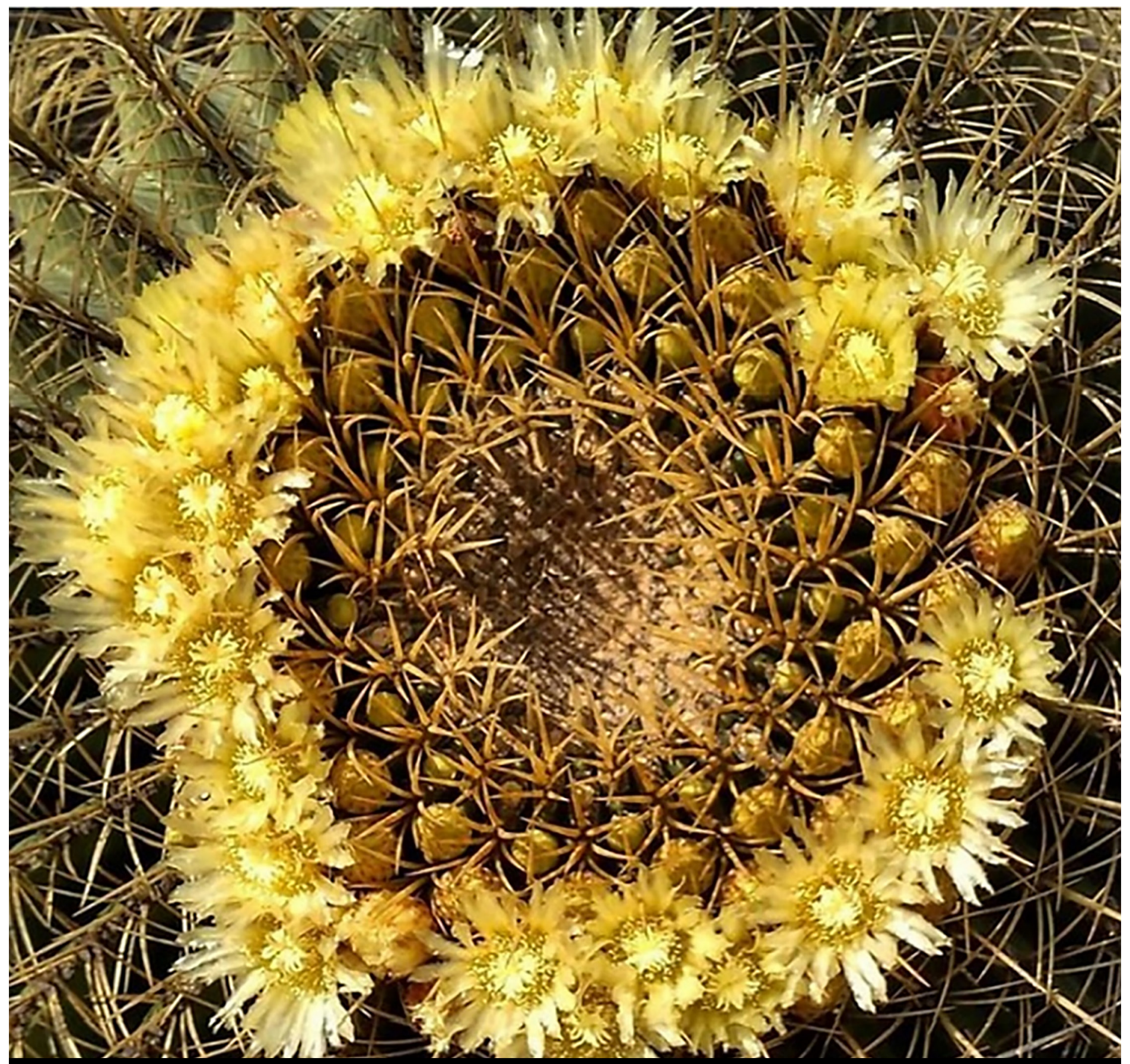

Corona de biznaga del género Echinocactus, especie sujeta a protección especial en San Agustín Tlaxiaca, Hidalgo. Fotografía: Susana Hernández Sánchez. 


\section{Reproducción y conservación in vitro}

Muchas han sido las especies propagadas mediante esta técnica biotecnológica, a continuación se presentan tres ejemplos de éxito en México que han utilizado el cultivo de tejidos vegetales como herramienta para investigar, conservar y mejorar las especies.

Dentro de la familia de las orquídeas existe una particularidad que le suma importancia al cultivo de tejidos vegetales, ya que el tamaño de sus semillas es muy pequeño y en condiciones naturales son muy difíciles de proliferar, además de que requieren la asociación de hongos para poder germinar. Afortunadamente, esta tecnología permite superar estas barreras biológicas y generar nuevas plantas. La vainilla (Vanilla planifolia) es una orquídea originaria de México que se encuentra bajo la categoría de protección especial (SEMARNAT, 2010), debido a su forma de cultivo (clonal) y la fuerte presión de selección, lo que ha originado la pérdida de su variabilidad genética haciéndola susceptible a enfermedades y menos hábil para adaptarse a cambios climáticos (RamírezMosqueda et al., 2018). Por otra parte, la vainillina, compuesto químico utilizado en la industria alimenticia, farmacéutica y cosmética, sigue siendo un producto de gran demanda a nivel internacional. Aunque se le han atribuido diversos usos medicinales, en realidad se trata de un compuesto sintético - el más comercializado en el país-, al que se atribuyen daños a la salud (Castelán-Culebro et al., 2020a).

En este sentido, la biotecnología ofrece alternativas para el rescate de este cultivo de gran interés económico. En Veracruz, en donde se encuentran los principales vainilleros y hay centros de investigación que cuentan con laboratorios especiales para este cultivo, se buscan parientes silvestres de la vainilla para poder aumentar la variabilidad genética, generar híbridos y mejorar el cultivo para rescatar la especie y lograr que esta actividad económica vuelva a ser reconocida en México. México pasó de ser el centro de origen y domesticación de la vainilla, a ser un país que no exporta este producto. Países como Madagascar, Indonesia y Francia son los que llevan la delantera en su comercialización (Castelán-Culebro et al., 2020b). Por lo tanto, consumir los productos naturales extraídos de forma sustentable ayuda a conservar la especie, la economía local y la conservación de selvas y bosques tropicales en donde es cultivada.

Otro ejemplo son los agaves, plantas que representan gran interés cultural, económico y ecológico en el territorio mexicano. Cabe resaltar que en el continente americano existen más de 200 especies de agave, y el 75\% se encuentra en nuestro país (Trejo-Hernández et al., 2016). Los agaves no solo son importantes en la producción de bebidas como el pulque y el mezcal, o como plantas de ornato, sino que cumplen tareas muy peculiares dentro del ecosistema como la reducción de la erosión de los suelos y son alimento y refugio para varias especies de animales, por ello es que también se les conoce como el "árbol de la vida" pues ofrecen inagotables recursos.

En Tlaxcala se cuenta con un centro de investigación dedicado al rescate del agave, el Laboratorio Regional de Biodiversidad y Cultivo de Tejidos Vegetales, en el cual se estudia su morfología,
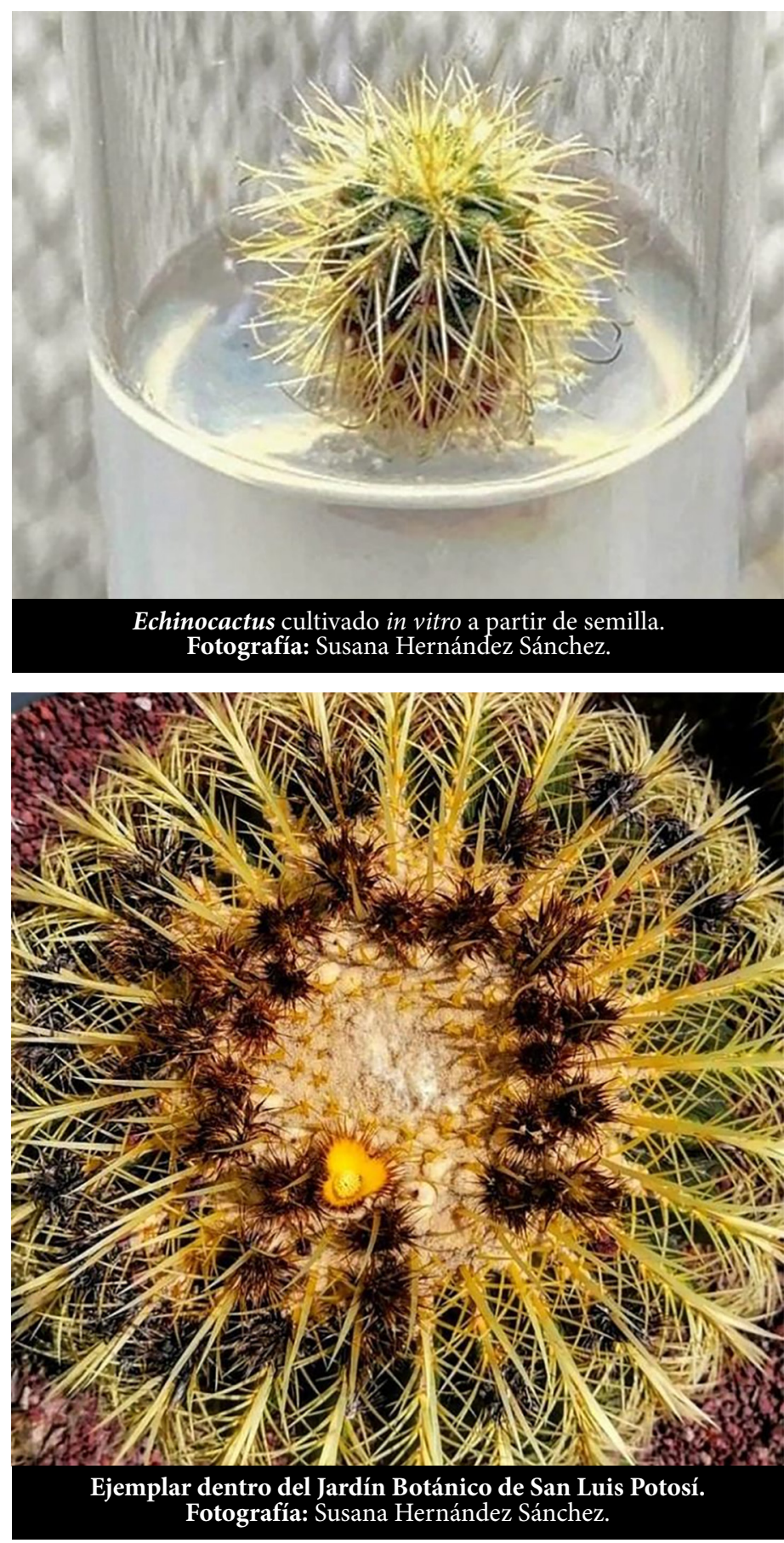

genética y se evalúan diferentes protocolos para propagarlos mediante procesos in vitro. Por ejemplo, las semillas de agave después de pasar por una fase de esterilización y desinfección superficial, se colocan dentro de un gel con nutrientes en donde pueden germinar en dos días, en contraste de las condiciones naturales que pueden retrasar el proceso hasta tres meses. Cuando el agave alcanza una talla adecuada, se lleva al invernadero y posteriormente se pasa al campo, donde terminará de crecer.

El tercer ejemplo son las cícadas, un grupo muy peculiar de plantas que han existido desde el Jurásico, por lo que convivieron con los dinosaurios. En nuestro país existen más de 54 especies, de las cuales se estima que 49 son endémicas (NicolandeMorejón y Martínez-Domínguez, 2017). Son un grupo de plantas que se encuentra protegido por estatus nacionales 
e internacionales, debido al alto índice de deforestación, fragmentación de los hábitats, pérdida de poblaciones y extracción ilegal. Además, los científicos hacen todo lo posible por encontrar alternativas para evitar su extinción mediante el uso de CTV. Así han logrado regenerar nuevas plantas a partir de fragmentos de hojas o con semillas (Cabrera-Hilerio et al., 2008).

Existe una larga lista de especies en peligro de extinción, amenazadas o sujetas a protección especial con las cuales se está trabajando en su conservación mediante el cultivo de tejidos vegetales.

\section{Soluciones y perspectivas}

El CTV es una técnica que en los últimos años ha ganado gran popularidad en el país debido a su alto potencial y amplia aplicabilidad. En este sentido parece ser una alternativa eficaz para aumentar la densidad de las poblaciones, cultivos masivos de especies y el uso sustentable de la biodiversidad.

Si bien es cierto que esta técnica es una excelente opción para salvar la flora mexicana, también es cierto que cada especie requiere un protocolo de investigación particular para su establecimiento. Por lo tanto, es necesario buscar alternativas que permitan generar material vegetal en menor tiempo y con mayor cantidad en comparación con las condiciones naturales, por lo que esta tecnología es viable en proyectos de reintroducción de ejemplares en sus hábitats y recuperación de los ecosistemas.

Por último, para la conservación de las plantas mexicanas se necesita hacer uso de técnicas y personal multidisciplinario, que la sociedad y la comunidad científica mantengan vínculos de conocimiento y soluciones a problemáticas nacionales. Así mismo, dentro de las acciones para la protección a la flora, se encuentran contemplados los jardines botánicos, bancos de germoplasma, comunidades y diversas instituciones de investigación como universidades, para realizar intercambio de ejemplares, proyectos y programas de recuperación.

Glosario
Generación de híbridos. Obtención de plantas producidas
por el cruzamiento de dos variedades o especies
genéticamente diferentes.
Mejoramiento genético. Conjunto de operaciones para
obtener individuos con las características deseadas.
Micropropagación. Técnica del cultivo in vitro para
propagar plantas a partir de un fragmento o explante de
una planta madre, del cual se obtendrá una descendencia
uniforme o clones.
Sanidad vegetal. Obtención de plantas de calidad y libres
de enfermedades.
Variabilidad genética. Diferencias genéticas entre
individuos o poblaciones, que influyen en su forma,
función, color, cualidades específicas como sabor,
resistencia, etc.

\section{Referencias}

Cabrera-Hilerio, S., Chávez-Ávila, V., Sandoval-Zapotitla, E., Litz, R. y Cruz-Sosa, F. 2008. Morfogénesis in vitro de Dioon merolae de Luca, Sabato \& Vázquez-Torres (Zamiaceae, Cycadales) a partir de megagametofitos y embriones cigóticos. Interciencia, 33 (12): 929934. Recuperado de http://ve.scielo.org/scielo.php?script=sci arttext\&pid=S037818442008001200013\&Ing=es\&tlng=es.

Castelán-Culebro, S., Franceschy-Ronzón, C. y Menchaca-García, R. 2020a. Extracto de vainilla ¿Natural o sintético? Vainilla de México para el mundo. Centro de Investigaciones Tropicales, Universidad Veracruzana, México.

Castelán-Culebro, S., Franceschy-Ronzón, C. y Menchaca-García, R. 2020b. La vainilla: más allá de su sabor. Vainilla de México para el mundo. Centro de Investigaciones Tropicales, Universidad Veracruzana, México.

Chávez-Ávila, V. 2014. Cultivan en la UNAM tejidos vegetales para conservar plantas mexicanas en peligro de extinción. Boletín UNAM-DGCS-010. Ciudad Universitaria. Recuperado de https:// www.dgcs.unam.mx/boletin/bdboletin/2014_010.html

Domínguez-Rosales, M. S., González-Jiménez, M., Rosales-Gómez, C., Quiñones-Valles, C., Delgadillo-Díaz de León, S., MirelesOrdaz, S. J. y Pérez-Molphe Balch, E. 2008. El cultivo in vitro como herramienta para el aprovechamiento, mejoramiento y conservación de especies del género Agave. Investigación y Ciencia, 16 (41): 53-62.

Nicolande-Morejón, F. y Martínez-Domínguez, L. 2017. Las cícadas, habitantes del Jurásico. La ciencia y el hombre, Revista de Divulgación Científica de la Universidad Veracruzana, 3 (30): 34 39.

Ramírez-Mosqueda, M., Iglesias-Andreu, L., Noa-Carranza, J. y ArmasSilva, A. 2018. Selección de genotipos de Vanilla planifolia Jacks. ex Andrews resistente a Fusarium oxysporum f. sp. Vanillae, mediante biotecnología. Agroproductividad, 11 (3): 70-74.

SEMARNAT (Secretaría del Medio Ambiente y Recursos Naturales). 2010. Norma Oficial Mexicana NOM-059-SEMARNAT-2010, Protección ambiental Especies nativas de México de flora y fauna silvestres Categorías de riesgo y especificaciones para su inclusión, exclusión o cambio Lista de especies en riesgo. Diario Oficial de la Federación. Recuperado de: https://biblioteca.semarnat.gob.mx/ janium/Documentos/Ciga/agenda/DOFsr/DO2454.pdf

SEMARNAT (Secretaría del Medio Ambiente y Recursos Naturales). 2012 Biodiversidad. En SEMARNAT (ed. 2012) Informe de la situación del medio ambiente en México, México, p. 156-167. Recuperado de https://apps1.semarnat.gob.mx:8443/dgeia/informe_12/pdf/ Cap4_biodiversidad.pdf

Trejo-Hernández, L., Martínez-Rendón, A. y López-Escamilla, A. 2016 Apoya la UNAM a comunidades de Tlaxcala a rescatar cultivos de Agave. Boletín UNAM-DGCS-492. Ciudad Universitaria. Recuperado de https://www.dgcs.unam.mx/boletin/ bdboletin/2016_492.html

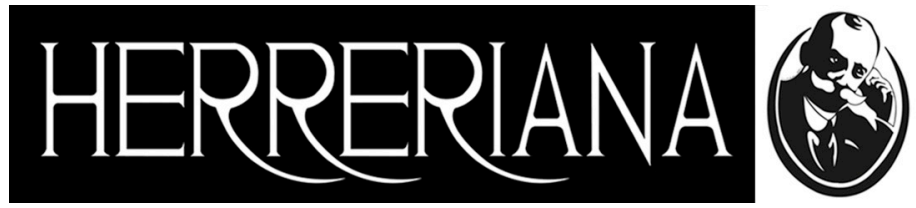

